De entrevistas 


\title{
Antonio Candido por ele mesmo: a entrevista como momento de mediação
}

\author{
Marcos Rogério Cordeiro* \\ Ivanete Bernardino Soares**
}

\section{RESUMO}

Antonio Candido concedeu inúmeras entrevistas ao longo da vida, oportunidade para não somente aprofundar questões pontuais de sua produção intelectual, como também para estabelecer os devidos vínculos e implicações entre elas. Arranjados em tom coloquial e próximo, esses depoimentos apresentam uma profundidade inquestionável, colocando o papel das ideias em comunicação com o momento histórico vivido e a visão de mundo do autor. Este artigo tem o objetivo de analisar o conteúdo desses depoimentos, procurando assim situar - por meio das considerações do próprio Antonio Candido a posição como intelectual diante de seus objetos de reflexão e estudo, bem como a concepção de política, sociedade e educação, atentando para o seu caráter integrativo, pautado por um trabalho de mediação de conceitos e princípios que irão marcar a personalidade de nosso homenageado.

Palavras-chave: Antonio Candido. Entrevista. Crítica. Educação. Pensamento de Esquerda.

* Universidade Federal de Minas Gerais (UFMG) . Doutor em Letras pela Universidade Federal do Rio de Janeiro. Professor adjunto III da Universidade Federal de Minas Gerais.

**Universidade Federal de Ouro Preto (UFOP). Doutora em Estudos Linguísticos pela Universidade Federal de Minas Gerais (2010/2013), na área de Linguística do Texto e do Discurso. Professora adjunta. 


\section{Antonio Candido by Himself: the Interview as a Mediation Moment}

\section{ABSTRACT}

Antonio Candido has given many interviews throughout his life. Each of these interviews amounts to an opportunity not only to go deep into punctual matters within his intellectual production, but also to establish the due ties and implications among them. Arranged in a colloquial and intimate tone, such testimonies present invaluable depth, placing the role ideas play in communication with the historical moment he happens to be living at the time and his authorial worldview. This paper aims at analyzing the content of these testimonies, and therefore trying to locate - by means of Antonio Candido's own considerations - his position as an intellectual before his objects of reflection and study. Moreover, we will scrutinize his conceptions of politics, society and education, paying attention to their integrative character, and we will be guided in this scrutiny by the mediation work that concepts and principles show, which will imprint their mark onto the personality of the scholar we are here paying homage to.

Keywords: Antonio Candido; Interview; Critique; Education; Leftist Reasoning. 


\section{Introdução}

Sem favor a Antonio Candido, não seria exagero dizer que se trata do intelectual brasileiro mais completo da história cultural moderna do País. Como professor e ensaísta, atuou em diferentes áreas do conhecimento das chamadas Humanidades: história, sociologia, teoria e crítica literárias, antropologia, política e educação. Não da mesma forma, em cada uma contribuiu de maneira a imprimir novidade, depurando conceitos e métodos, reelaborando conteúdos, avançando em campos logo incorporados à rotina de pesquisas. Algumas dessas conquistas foram reconhecidas, outras contestadas (muitas vezes sem uma apreciação à altura), outras ainda esperam investigação pausada, com chave que talvez só o tempo e suas mudanças poderão oferecer. No começo da carreira universitária, com 27 anos de idade, escreveu um trabalho no qual discutia o papel dos conceitos na crítica e na historiografia literárias, $\mathbf{O}$ método crítico de Sílvio Romero (1945); ${ }^{1}$ pouco depois começou sua tese em sociologia, com forte acento antropológico e entradas nas geografias humana e social, Os parceiros do Rio Bonito (1964); ${ }^{2}$ ao mesmo tempo, desenvolveu sua obra magna, Formação da literatura brasileira (1959), ${ }^{3}$ um livro cheio de erudição,

1 Apresentado nesse mesmo ano como tese para o concurso de Literatura Brasileira na Universidade de São Paulo. Nessa época, Antonio Candido já era professor assistente de sociologia na mesma instituição, tarefa que desempenhou até 1963, quando passou a se dedicar exclusivamente aos estudos literários. A tese foi aprovada, mas não classificada (CANDIDO, 1988a).

2 O trabalho teve início em 1942, foi apresentado em 1954 com o título de Os parceiros do Rio Bonito: estudo sobre a crise dos meios de subsistência do caipira paulista; a publicação saiu em 1964, com o subtítulo um pouco modificado. As referências deste e dos demais livros de Antonio Candido se encontram no fim deste artigo (CANDIDO, 2001a).

3 O livro começou a ser escrito em meados dos anos 1940 e foi concluído 
com volume expressivo de material consultado, expondo com a devida profundidade e clareza a articulação de um processo muito matizado; a esses acrescentem diversos estudos de análise literária, que começaram em jornais e revistas na década de 1940 e se estenderam por mais de sessenta anos, sendo a atividade de que mais gostava. Antonio Candido escreveu também artigos de intervenção no âmbito da política, da vida social e da educação, além de atuar na articulação de grupos e partidos, na consolidação de departamentos universitários, associações acadêmicas de pesquisa, e de se desdobrar nas tarefas docentes e de orientação.

Apresentadoassim, pode parecerquese trata deumintelectual multifacetado, com interesses e descobertas independentes, realizados em campos de saber autônomos. Mas, ao contrário, o que se observa em uma leitura atenta de sua obra é a força de coesão do conjunto. Ou seja, os estudos historiográficos, políticos ou de análise e interpretação, não obstante as especificidades, são atravessados por preocupações comuns e por uma lógica de reflexão e de princípios. Por isso, em vez de falarmos da crítica, da teoria, das intervenções públicas e da história nos diversos textos de Antonio Candido, procuraremos tratar de linhas de força comuns que atravessam esses escritos e que, de certa maneira, foram estabelecidas por ele mesmo: o primado da clareza e do discernimento, a perspectivação crítica pelo ângulo ideológico de esquerda e o sentimento materialista dos processos. Tratam-se de princípios ordenadores que delimitam o campo de interesse e direcionam o ângulo dos argumentos; são fatores de mediação que desenham não só um perfil intelectual, mas também de personalidade, um diferencial que se reconhece

em 1959, data de sua publicação. O período coincide com a feitura da tese de sociologia que, durante alguns anos, Antonio Candido preparou conjuntamente (CANDIDO, 2006c). 
melhor nas entrevistas do que nos escritos acadêmicos. A bem da verdade, as tais mediações podem perfeitamente ser descobertas na leitura atenta dos ensaios de Antonio Candido - trata-se de uma condição objetiva, manifesta na matéria desses escritos -, mas, no âmbito das entrevistas, elas aparecem mais franqueadas, expostas de viva voz, digamos assim. A entrevista, aliás, como gênero com características próprias, e a depender das condições de sua produção, permite uma interação espontânea e direta, sem os preâmbulos e remissões externas - inevitáveis no ensaio e no artigo - que poderiam modalizar ou diluir posicionamentos de base. No caso particular das entrevistas de Antônio Candido, sabemos que muitas respostas dadas foram editadas por ele $a$ posteriori, quando não completamente elaboradas à distância, diferenciando o tempo da interpelação e o tempo da resposta. Essa circunstância de sua produção acarreta a particularidade genérica dessas entrevistas ao temperar o encadeamento espontâneo das respostas com a precisão histórica e referencial das informações, atribuindo à expressão a tonalidade professoral de uma aula planejada.

Se, por um lado, a entrevista se estrutura na descontinuidade e variação de temas no curto espaço de tempo em que se realiza, por outro, favorece o estabelecimento de um fio condutor da coerência do entrevistado. Neste trabalho, interessa particularmente deslindar esse eixo de articulação das concepções de Candido sobre objetos variados (política, crítica, educação etc.), ampliando a compreensão de sua atuação intelectual.

Como mais uma demão do gênero textual escolhido para alcançar o cerne do pensamento de Candido, é preciso dizer ainda sobre os entrevistadores que são na sua maioria conhecedores de sua obra e vida, ex-alunos, correligionários, pesquisadores ou especialistas nas áreas afins de sua atuação, favorecendo o 
aprofundamento de remissões e lembranças. Destaque-se ainda que Antonio Candido concedeu muitas entrevistas, ${ }^{4}$ valendo remeter-se ao trabalho (ainda inédito) de Marcello Rollemberg, diretor de redação do Jornal da USP, que o entrevistou durante dois anos e recolheu vasto material, compondo um conjunto de depoimentos nos quais o entrevistado põe em perspectiva a própria vida, seu percurso formativo, rede de relações pessoais e frentes de atuação, encadeando-os com os acontecimentos históricos e políticos do País, que ele conhecia muito bem, pelos livros e por experiência própria. ${ }^{5}$ Não restam dúvidas, portanto, de que, no caso de Antonio Candido, a entrevista assume grande importância como instância de mediação das ideias.

Nosso interesse, contudo, não é destacar o indivíduo, mas um processo que se materializa através dele, em consonância com seu grupo, sua geração, sua ideologia, tudo isso formando uma totalidade de base histórica. Por isso, dizemos que suas conquistas intelectuais - decerto resultados de esforço e talento - devem ser encaradas como produtos de condições objetivas, desenvolvidas por alguém que soube internalizar a complexidade autotransformadora da realidade social que vivia.

\section{Opção pela clareza}

Dentre os predicados atribuídos a Antonio Candido por diferentes segmentos de leitores, a lucidez da expressão e o

4 Tomamos por base o levantamento criterioso de Vinícius Dantas, que registra mais de 50 entrevistas entre 1960 e 2001, mas é certo que Antonio Candido concedeu mais de uma dezena de entrevistas depois da publicação desse catálogo. Ver Dantas (2002, v. 2).

5 Segundo depoimento do próprio Marcello Rollemberg durante o simpósio "Homenagem ímpar: Candido, Schwarz e Alvim", realizado na Universidade de Brasília, nos dias 30 e 31 de agosto de 2017. No formato Word, o documento contava com quase 400 páginas. 
discernimento de seus juízos requerem uma apreciação mais demorada, para que se possa aferir, por trás de um estilo de linguagem, a postura ética e comprometida do intelectual diante da sociedade que analisa. Sua produção bibliográfica é marcada por uma precisão estilística peculiar no engendramento da reflexão que, por isso mesmo, se torna tangível, palpável. A clareza e fluidez da linguagem permitem a penetração das ideias na elaboração do raciocínio, de modo a acentuar mais a natureza do material problematizado do que as manobras retóricas típicas do discurso acadêmico. Um traço inerente de sua elocução, por exemplo, é o descaso pelo jargão científico, pelo acúmulo de rótulos conceituais das áreas que manipula, priorizando sempre a função comunicativa da linguagem, seu papel de mediadora entre indivíduos do conhecimento. Conhecimento e linguagem, aliás, formam uma unidade em favor da inteligibilidade da mensagem, quer ela trate de literatura ou política, traduzindo-se em um tipo de compromisso ético.

Penso que, nestas disciplinas humanas, a linguagem corrente é suficiente para escrevermos. De modo que eu fui assistente de Sociologia muito tempo, em Sociologia eu reagia contra isso também. Eu reagia contra aquela terminologia abstrusa que consiste frequentemente, nas disciplinas humanas, em dizer coisas simples de maneira complicada. ${ }^{6}$ Nós temos um pouco de complexo de inferioridade, sobretudo na minha geração; na minha geração nós estávamos ainda muito próximos do positivismo científico. (CANDIDO, 1997, p. 12).

Percebe-se aí a resistência à diç̧ão erudita, que elege artifícios linguageiros e acabam por maquiar aspectos da realidade

${ }_{6}$ Que sirva de contraponto uma passagem de Formação da Literatura Brasileira, na qual Antonio Candido explicita o método de exposição empregado na composição do livro: "E preciso ver simples onde é complexo". (CANDIDO, 2006c, p. 32). 
que deveriam ser, ao contrário, desvelados. Essa preferência pela linguagem escorreita se desdobra na consideração que dispensa ao leitor, e reforça o dever imposto ao estudioso das humanidades, já que lida com um tipo de complexidade bastante significativa do ponto de vista social:

Acho que a clareza é um respeito pelo próximo, um respeito pelo leitor. Sempre achei, eu e alguns colegas, que, quando se trata de ciências humanas, apesar de serem chamadas de ciências, são ligadas à nossa humanidade, de maneira que não deve haver jargão científico. Posso dizer o que tenho para dizer nas humanidades com a linguagem comum. Já no estudo das ciências humanas eu preconizava isso. (CANDIDO, 2011b, p. 1).

Essas razões de ordem ética e profissional se somam às de ordem prática, ligadas à sua atuação no jornalismo, nos primeiros anos de carreira, nos anos de 1940. A isso ele atribui a peculiaridade de sua escrita que, marcada pela conjunção da simplicidade da forma e complexidade da matéria, alcança a articulação da teoria acadêmica à criatividade pessoal:

Atento sobretudo à questão da simplicidade, que eu acho importante. Em primeiro lugar, talvez, por eu não ser formado em Letras. Sou formado em ciências sociais, então não aprendi aquela terminologia específica dos cursos de Letras. Em segundo lugar, pelo fato de eu ter começado a minha atividade literária como crítico de uma revista estudantil e em seguida como crítico de um jornal de São Paulo, portanto veículos que exigem a comunicação. Eu creio que a minha experiência de jornalista-crítico foi fundamental. (CANDIDO, 1997, p. 11).

A vivência do jovem Candido com a crítica regular em revistas e jornais exigia um contato desimpedido com um 
público muito diverso, o que só poderia ser feito por meio de um estilo de linguagem inteligível e democrático. Talvez por isso tenha eleito como forma textual privilegiada para a divulgação de seus estudos o ensaio, gênero que se vale da elocução oral e reproduz, por meio do fluxo de consciência e evitando os jargões acadêmicos, o movimento da matéria. Orientando-se pela dinâmica do pensamento surpreendido em ato, o ensaio permite, portanto, a profundidade da reflexão revestida pela simplicidade da expressão. ${ }^{7}$ Nesse caso, o ensaio acomoda convenientemente a atitude eclética do crítico e seu temperamento pessoal, avesso a sectarismos e sempre disposto a considerar o contraditório proceder natural de "quem passa a vida mexendo com literatura, vendo as análises sutis do comportamento, pesando os prós e os contras, [e que por isso] tem certa dificuldade em aceitar ou rejeitar em bloco". (CANDIDO, 1988b, p. 10).

Emoldurando e provendo esse estilo discursivo, manifestase nos textos de Candido uma aptidão para a comunicação direta e objetiva, anunciando o traço de uma personalidade profundamente marcada pela despretensão:

Nunca pensei que fosse publicar alguma coisa. A minha vocação foi sempre de leitor e desde os nove anos li muito, de maneira dispersa e variada, de modo que acumulei desde cedo muita informação, mas não sei nada a fundo nem tenho temperamento de especialista. (CANDIDO, 2001b, p. 22).

O zelo pela clareza e o feitio descomplicado de sua produção acadêmica parece encontrar fundamento último em sua "personalidade de educador", como foi caracterizado pelo

7 A respeito das particularidades formais e discursivas do ensaio realizado por Antonio Candido, ver Arrigucci Jr. (1992); Claro (1992); Chiappini (1999). 
amigo Florestan Fernandes, segundo o qual Antonio Candido teria "calibrado sua imaginação pedagógica a partir daquele que devia aprender (nunca do que devia ensinar)" (FERNANDES, 1992, p. 33-34), prezando mais a expectativa de interlocução e a necessidade de conhecimento, que a vaidade do intelectual. Nessa direção, para além da coloração de comunicador não aclimatado à linguagem especializada, podemos inferir ainda, uma motivação mais sutil, associada agora ao ofício da docência. Nas entrevistas predominantemente de cunho biográfico-intelectual, Candido manifesta de modo recorrente sua admiração por professores que influíram intimamente na sua formação profissional e mesmo pessoal. As caracterizações dos perfis esboçados por Candido revelam um ideal de conduta que certamente contribuiu para formar sua rede de referências sobre a necessidade da clareza na exposição, sobre a excelência do professor e, de resto, sobre a função do intelectual. Na sequência, selecionamos trechos em que acentua as características que qualificaram dois de seus grandes mestres, Roger Bastide e, em especial, Jean Maugüé:

Bastide era um homenzinho com cara de chinês, muito bondoso, generoso, tranquilo, de uma grande sabedoria e professor excelente. Ele não tinha preconceitos teóricos e metodológicos. [...] atendia os alunos com solicitude e delicadeza, dava orientação bibliográfica por escrito e até emprestava as notas de aula. Nas aulas começava sempre comentando a bibliografia a respeito do assunto, depois passava à crítica e acabava apresentando seu ponto de vista (CANDIDO, 2001b, p. 11-12).

[Maugüé] era um gênio didático, um expositor elegante, expressivo e penetrante, tinha uma inteligência original, pronta e luminosa, completada por uma imaginação fora do comum e o mais incrível senso do auditório. [...] Maugüé não fazia questão de publicar nem de "fazer currículo", que, como vocês sabem, é muitas vezes uma operação farisaica. Ele estava interessado em 
compreender a vida, as obras, as pessoas, e despertar nos alunos uma atitude semelhante. Nesse sentido era tipo socrático e se realizava falando, não escrevendo. (CANDIDO, 2001b, p. 13).

[Maugüé] começava geralmente como se estivesse hesitando, tateava e de repente engrenava e se punha a expor com uma clareza, uma elegância e uma competência incríveis, tornando interessante qualquer matéria. Não era propriamente filósofo, mas um excelente professor de filosofia. (CANDIDO, 2001b, p. 14).

Nesses fragmentos, é possível identificar uma série de características reconhecida como próprias: a ausência de preconceitos teórico-metodológicos admitindo frequentemente seu "ecletismo" ("Fui me inclinando cada vez mais para uma crítica integrativa" - CANDIDO, 2006a, p. 36); o interesse pela sociologia acima de tudo para compreender a vida, as pessoas, a sociedade e não para fazer carreira ("Optei pelas Ciências Sociais, porque desejava entender bem a sociedade brasileira" - CANDIDO, 2006b, p. 26); a preferência pela elocução oral ("Sou um homem mais de palavra falada que de palavra escrita" - CANDIDO, 1997, p. 13) e o reconhecimento de que era mais um professor do que um especialista ("Eu não me considero sociólogo. Assim como o professor de matemática não é necessariamente matemático, fui professor de sociologia, dei conta do recado, mas nunca me considerei sociólogo" CANDIDO, 2002, p. 125).

Os demais predicados apontados em seus mestres ecoam também nos depoimentos de ex-alunos, comprovando o êxito de Candido na replicação dos modelos que admirava: a clareza sempre aliada à profundidade no tratamento dos assuntos, o investimento extra na aprendizagem do aluno e a perícia na gestão 
da sala de aula. ${ }^{8}$ Nesse comportamento, há muitos pressupostos de uma concepção de educação pautada no reconhecimento de sua função emancipadora e na socialização do conhecimento como ato político, no sentido amplo. Além de sua escrita didática, seu interesse pela qualificação do ofício docente manifesta-se também em publicações baseadas precisamente na transposição didática do exercício da crítica, como é o caso de Na sala de aula: cadernos de análise literária (1999) e O estudo analítico do poema (2006d). Assim, a confluência formal entre a conversação refinada e a escrita ensaística parece encontrar a justificativa na experiência pedagógica:

Sou sobretudo professor, sou um homem de expressão oral, sou conversador, sou um contador de causos. De modo que tenho a impressão que o ritmo da fala deve passar pelo ritmo da minha escrita. Talvez por isso ela seja frequentemente acoimada de ser uma escrita pouco profunda. É uma escrita clara, mas pouco profunda, porque há um pouco essa ideia de que a clareza frequentemente é obtida à custa da profundidade, o que é uma ideia válida. Entre clareza e profundidade, eu prefiro a clareza, mesmo porque eu não sou capaz de chegar na profundidade. É verdade, sem falsa modéstia nenhuma, eu me considero um professor, um expositor. (CANDIDO, 1997, p. 13).

Destaca-se, nessa passagem, o protagonismo da atividade docente na orientação comunicativa de sua produção intelectual, o que o leva a afirmar objetivamente: "quando escrevo, é o professor que está falando". (CANDIDO, 1997, p. 14). Aliás, diante de uma questão sobre como levar o cânone para o não leitor, Candido, após apresentar um exemplo bem-sucedido, conclui que, para isso, "tem que saber explicar, usar a linguagem normal". (CANDIDO, 2011b, p. 3).

8 Ver Arrigucci Jr (1992); Cardoso (1992); Carvalhosa (1999); Chiappini (1999); Claro (1992); Fernandes (1992); Abramovich (1990). 
Tomando recuo, podemos aferir também um posicionamento dirigido pelo senso de justiça e pelos ideais de igualdade que, como se verá mais a frente, sempre apregoou como homem político. A clareza da linguagem informada pelo desvelamento da complexidade das relações sociais em variados estratos de análise permitiria, desse modo, o acesso democrático às descobertas “científicas” que, necessariamente, não precisariam ser "abstrusas" ao pensamento médio, além de funcionar como mecanismo de desenvolvimento humanizador: "A busca de uma linguagem simples me pareceu sempre um instrumento de humanização, e eu procuro isso". (CANDIDO, 1997, p. 12). O humanismo inscrito aí não se esgota em si mesmo, mas se configura em face da sociedade, suas contradições históricas, suas desigualdades econômicas e de oportunidades. Ou seja, Antonio Candido historiciza sua própria posição como partidário da clarificação da matéria a qual sua linguagem se dedica a compreender e explicar: "Qualquer atividade que não seja estritamente técnica, acho que a clareza é necessária, inclusive para poder divulgar a mensagem, a mensagem deixa de ser um privilégio e se torna bem comum". (CANDIDO, 2011b, p. 1).

Por essa via, voltamos ao compromisso com a função humanizadora da linguagem, que desobstrui o acesso ao conhecimento por intermédio da clareza e revela, no professor, sua atuação solidária (e, no limite, politizada, como veremos) com a partilha democrática do conhecimento. Em Candido, o esforço pela maestria no ensino combinado com o pendor ético para um "socialismo democrático" militante (CANDIDO, 2011b, p. 5) qualifica sua atuação como um ato político de grande força de ação, reinserindo os objetos do conhecimento no contexto das relações coletivas, espaço de conflito de interesses das classes sociais. 


\section{Viés de esquerda}

Como se viu, o ideal de clareza atravessa diferentes âmbitos, interligando reflexão teórica, prática de ensino, intervenção política etc., conferindo a eles um ar de família. Podemos atribuir essa condição às especificidades da entrevista como gênero, que naturalmente intercala os assuntos, ou podemos reconhecer como traço de personalidade do entrevistado, cujo caráter se conforma no interior das ideias e posições que assume e defende. Mas podemos ainda - como é nosso interesse reconhecer o entrelace objetivo desses diferentes temas, a ver como sua opção pela clareza se desdobra em uma perspectiva ideologicamente crítica. Em outras palavras, pensamos que, por meio da inteligibilidade veiculada na linguagem, Antonio Candido exerce papel político de homem de esquerda, na medida em que a clarificação deve promover a socialização cultural, política e econômica (CANDIDO, 1997). Essa postura despontou cedo e foi sendo aprofundada e depurada no correr dos anos. Trabalhando a cabeça para alcançar sua razão de ser, ele explica as transformações que ocorreram dentro de si mesmo como resposta individualizada das condicionantes externas - uma postura materialista, como veremos adiante. O contato pessoal com professores e amigos impressionaram o jovem Antonio Candido e influenciaram também sua experiência com as ideias socialistas, começadas na pequena Poços de Caldas, interior mineiro, onde passou infância e adolescência:

Creio que o primeiro estímulo veio de um colega do ginásio. $\mathrm{O}$ pai dele tinha sido garçom, era hoteleiro e anarco-sindicalista. Por intermédio dele tomei conhecimento de obras de anarquistas como Everardo Dias, Jean Grave, Severine, Kropotkin, Sébastien 
Faure. E li também o resumo de $\mathbf{O}$ capital por Gabriel

Deville. Mas nada calou muito fundo. (CANDIDO, 1988a, p. 1-2).

Como se vê, a leitura começou cedo, mas não penetrou o espírito do garoto, ao contrário da convivência com uma senhora, vizinha dos pais, Teresina Maria Carini Rochi, sobre quem Antonio Candido escreveu um ensaio biográfico muito cuidadoso e cheio de admiração: ${ }^{9}$

Dona Teresina Rochi era uma mulher extraordinária. Era bem pobre, mas quem batesse na porta e pedisse dinheiro sempre recebia alguma coisa, mesmo que ela ficasse sem um tostão. Nunca vi desprendimento mais completo, nem menos senso de propriedade. Foi militante aqui em São Paulo no começo do século, era socialista revolucionária, ligada aos anarquistas, e tinha muita simpatia pela Revolução Russa. (CANDIDO, 1988b, p. 1).

Ela não se conformava que o socialista fosse rico e fosse socialista. O socialista é a pessoa que tem que praticar na sua vida a distribuição dos bens. [...] Então, o socialismo para ela era um modo de ser, era solidariedade, camaradagem, compreensão, senso de igualdade. (CANDIDO, 1997, p. 35-36).

É do exemplo de vida de D. Teresina que Antonio Candido constrói para si uma concepção humanista voltada para as condições sociais. Essa impressão mais pessoal e não livresca com certeza lhe "calou fundo", até o ponto de se tornar uma convicção arraigada:

Chamo socialista todas as tendências que dizem que o homem tem que caminhar para a igualdade e que ele é o criador de riquezas e não pode ser explorado. (CANDIDO, 2011b, p. 4).

9 Ver Candido (1992a). 
Porque a tônica maior do socialismo é a igualdade, não a liberdade. Nós temos uma obsessão muito grande com a liberdade, e talvez eu choque dizendo que se tivermos de escolher entre liberdade e igualdade, nós devemos escolher a igualdade, não a liberdade. Porque a liberdade é sempre minha liberdade e a igualdade por definição é de todos. (CANDIDO, 1997, p. 25).

É desse ideal que surge a noção de humanismo socialista e solidário, ainda sob a impressão da figura de D. Teresina: "Ela me transmitiu sobretudo a afetividade socialista, que acho fundamental." (CANDIDO, 1988b, p. 1). Trata-se de uma concepção diferente, não oposta nem alternativa, mas complementar ao socialismo propriamente político, resultado de uma atuação coordenada, coletiva, orientada por princípios ideológicos e atividades dirigidas, algo a que Antonio Candido se acostumou também devido às amizades, especialmente a de Paulo Emílio Salles Gomes: "Ele foi a grande influência que sofri. Da nossa turma, era o único que tinha verdadeira experiência e verdadeira consciência política." (CANDIDO, 1988b, p. 4). Anos mais tarde, no rescaldo da ditadura e sua rede de repressão e desmobilização, deveu a outro companheiro sua filiação ao Partido dos Trabalhadores:

Eu entrei no PT sobretudo por causa dos meus amigos mortos, por causa do Paulo Emílio [Salles Gomes] e do [Febus] Gikovate. O Gikovate, pouco antes de morrer, me deu a tarefa de entrar no PT. Uma coisa muito comovente. Nós fomos vê-lo no hospital. Eu entrei, ele sentado na cama, eu disse: "Meu chefe, vim aqui transmitir a você um convite. Estão cuidando de formar um partido e estão nos convidando. Mas eu não vou", eu disse para ele. E ele me disse: "Você faz muito mal. Você deve ir. Porque este partido é finalmente a realização de nossos ideais. Porque é um partido socialista, independente, com base operária. [...] E eu peço mais, peço a você que vá e que diga às 
pessoas que estiverem lá que eu não vou porque estou indo para outro lugar." Morreu no dia seguinte. (TRÊS ANTÔNIOS, [1993]/2017).

Esse episódio explica uma ponderação recorrente de Antonio Candido a respeito de sua atuação política: "Eu sou um mal político, apenas segui os meus amigos." (CANDIDO, 1988b, p. 1). Não obstante a sinceridade crua, sem afetação de modéstia e despintando uma imagem que se consolidou em torno de sua pessoa, Candido traça um perfil mais completo ancorado em sua visão de mundo e personalidade: "Não tenho vocação política. Para mim, a participação foi sempre um dever moral, despertado pelo sentimento de justiça e a convicção de que o socialismo é a melhor fórmula para organizar a sociedade." (CANDIDO, 1988 b, p. 10). Nessas palavras, ficam registradas as lições de "afetividade socialista" de D. Teresina. A contraparte vem de um acentuado grau de instrução política, algo que Antonio Candido aprendeu a realimentar na experiência universitária.

Como vimos, as primeiras leituras socialistas não "calaram fundo". Ao se estabelecer em São Paulo para completar os estudos secundários, como admite, ficou seduzido pelos atrativos da cidade grande, as livrarias, os teatros, os bares de chope (CANDIDO, 1988b, 2001b). Mas, ao ingressar no curso de Sociologia na Universidade de São Paulo, a cultura política dos livros passa a concorrer com o sentimento socialista para compor um universo intelectual voltado para as pessoas em sociedade. Entre professores mais ou menos progressistas, mais ou menos conservadores, as referências bibliográficas, o método de aprendizagem e reflexão se diversificavam. Na lista de autores lidos por Candido, constam nomes como Adam Smith, Malinowski, Weber, Durkheim e, ainda, Radcliffe-Brown, que influenciou sua ideia de estrutura como algo dinâmico. 
Mas o autor que parece ter marcado mais profundamente Antonio Candido foi Karl Marx, influência condicionada em parte também pela experiência universitária com Maugüé: “O professor que mais me influenciou foi o de História da Filosofia, Jean Maugüé, um marxista aberto." (CANDIDO, 2002, p. 157). A apropriação do marxismo por parte de Candido, no entanto, aparece controversa nas entrevistas: são muitas as passagens nas quais assume uma influência decisiva de Marx e outras em que afirma o contrário (em todo caso, é uma raridade não encontrar referências explícitas a Marx ou ao marxismo). Sirva a seguinte passagem de exemplo dessa atitude dúplice: "Portanto repito: sofri a influência do marxismo e basta ler o que escrevo para ver isso; mas nunca fui marxista propriamente dito e nunca quis me dizer marxista, para guardar essa liberdade, sobretudo no campo da arte." (CANDIDO, 1996, p. 16). A ambiguidade aparente da frase é superficial e esconde uma composição mais complexa, dependente da realidade histórica, da configuração do marxismo no período entreguerras e de sua recepção no Brasil.

Para compreender melhor do que se trata e não fabricar um falso problema, convém lembrar que Candido se refere sempre a um momento histórico preciso - décadas de 1930 e 1950 - e a uma determinada concepção do marxismo, que previa obediência às diretrizes táticas de ação que predominavam nessa época. Sob essas condições, originou-se no Brasil uma ideologia pragmática carente de reflexão sobre as particularidades do País e fraca em organização de classe, uma combinação de efeitos deletérios. ${ }^{10}$

Só com má-fé se poderia ver uma recusa indiscriminada do marxismo por parte de Antonio Candido; suas críticas são delimitadas e pontuais: "No meu tempo o marxismo

${ }^{10}$ Ver Konder (1988) e Moraes (1995). 
parecia frequentemente uma coisa religiosa, abrangente demais." (CANDIDO, 1996, p. 15). Mas a situação muda com o aprofundamento dos avanços do capitalismo no Brasil, durante o governo de Juscelino Kubitschek, e com a decorrente interpretação criteriosa da obra de Marx promovida por um grupo de jovens professores e estudantes de esquerda pertencentes aos quadros da Universidade de São Paulo. ${ }^{11}$ Antonio Candido, que conviveu com muitos membros do grupo, não o frequentou, $\mathrm{O}$ que evidentemente não o impediu de reconhecer-lhe o mérito, admitindo que "as gerações que vieram depois são muito mais informadas [em marxismo]." (CANDIDO, 1996, p. 15). Quanto ao aspecto mencionado por ele acima, referente à concepção de arte veiculada no marxismo, trata-se de uma questão de método, sobre o qual falaremos adiante. ${ }^{12}$

Seja como for, o marxismo se mostra uma contraparte teórica aproximativa do sentimento solidário, ajudando a consolidar, por outros meios, uma inclinação subjetiva. A esse quadro se soma ainda dois outros fatores, interligados pelas mediações históricas presentes. Primeiro, uma guinada de perspectiva das ciências humanas na faculdade em que atuava, o que o levou junto com sua geração à produção de trabalhos acadêmicos voltados para a análise da estrutura social brasileira, despertando interesse crítico pelos trabalhadores, negros, índios,

${ }^{11}$ Ver depoimentos de alguns integrantes desse grupo em Nós que amávamos tanto "O capital" (SCHWARZ et al, 2017) e em Retrato de grupo (MOURA; MONTERO, 2009). Um pouco depois, formaramse grupos com os mesmos interesses no Rio de Janeiro, a reunir Leandro Konder, Carlos Nelson Coutinho, José Paulo Neto, entre outros, e em Minas Gerais, em torno do professor José Chasin.

${ }^{12}$ Este é um problema que precisa ser circunstanciado; segundo as interpretações de Roberto Schwarz (1989), Paulo Arantes (1992) e Leopoldo Waizbort (2007), Antonio Candido representa um tipo de crítico marxista exigente e refinado, embora não faça praça da filiação. 
caiçaras e caipiras (CANDIDO, 2002), ou seja, as classes subalternas que estavam sofrendo uma mutação em decorrência do avanço do capitalismo no Brasil. Segundo, o processo de modernização capitalista ele mesmo, que alinhava uma pequena fração das classes dominantes ao mundo desenvolvido e deixava a grande massa presa às iniquidades do progresso, situação de aguda desigualdade social, contra a qual, como vimos, Candido se opunha de maneira inflexível. Daí a gestação dentro dele do que chamou de "pensamento radical" (CANDIDO, 1992b, p. 234-235): uma impregnação dos instrumentos de crítica voltada para as contradições do mundo social abrangendo a economia, a política, a cultura e as artes e que foi abraçada por um segmento progressista da classe média ilustrada e urbana.

\section{Senso do concreto}

A postura ideológica de Antonio Candido pressupõe uma compreensão da realidade histórica como processo heterogêneo, complexo, contraditório e, sobretudo, coerente, o que o leva a entender a desigualdade social, que tanto incomoda o socialista, não como imperfeição ou deformidade lateral, mas como parte essencial das leis de reprodução do sistema capitalista. Ora, esse tipo de aproximação para com o objeto corresponde aos postulados marxistas que delimitam um modo de reflexão baseado em conceitos pertencentes à ordem do real. Mesmo quando Antonio Candido não o chame pelo nome, trata-se de marxismo o modo como sua análise procura implicar a realidade histórico-social e as formas literárias, por exemplo, ou quando recorre às providências políticas e educacionais para superar a assimetria de classes. Em outras palavras, as reflexões de Antonio 
Candido possuem uma feição essencialmente materialista, uma percepção que abraça diversas frentes de atuação. Comentando a prática de pesquisa, ele faz um balanço: "Se há uma orientação geral da minha atividade, tanto no campo da sociologia como no da literatura, eu diria que é a paixão do concreto." (CANDIDO, 2002, p. 126). Apenas para ilustrar rapidamente, lembremos Os parceiros do Rio Bonito: o quadro de referências inclui autores das áreas de sociologia e antropologia, mas a inspiração e a orientação da pesquisa não vieram de conceitos formulados em livros e, sim, da observação da prática social de uma comunidade específica. Os resultados obtidos se destacam menos pela manipulação conceitual do objeto do que pelo vai e vem dialético entre a condição material de vida de uma certa camada social no interior paulista, o processo de transformação perpetrado pelo desenvolvimento mundial do capitalismo e seus reflexos no Brasil. O modo como esses âmbitos interagem no curso da história, ou seja, sua existência no âmbito do real, engendram os conceitos e esquemas de pensamento a partir dos quais Candido fundamenta suas análises. No caso de Formação da literatura brasileira - enquanto estudo historiográfico -, o materialismo não se encontra no levantamento de obras, autores, documentos e fatos, mas na estruturação do material, na ênfase do princípio explicador, no modo como a literatura vai entrelaçando temas e formas no decorrer do desenvolvimento histórico. As obras independentemente da qualidade - não são vistas como fatores isolados no mundo das letras, mas como produtos sociais:

Como dizia Mário de Andrade, o importante é uma literatura média, por que o gênio surge até no deserto do Saara, num oásis pode surgir a Odisseia. O gênio é uma coisa, a literatura é outra. A literatura é um processo histórico, de natureza estética, que se define pela inter- 
relação das pessoas que a praticam, que criam uma certa mentalidade e estabelecem uma certa tradição. (CANDIDO, 1997, p. 19).

A coloquialidade - linguagem característica da entrevista - não oblitera o foco da explicação, que é buscar compreender os fenômenos particulares em função de seu encadeamento objetivo, histórico. Esse procedimento se completa no método utilizado para análise do texto literário individual, que, em fase já amadurecida, é designado de "redução estrutural":"13 "Esta perspectiva me levou a refletir sobre o processo que estrutura a estrutura, que converte determinado aspecto social em obra literária." (CANDIDO, 1980, p. 5). O procedimento que "estrutura a estrutura" é dialético e depende, por sua vez, da estruturação histórica, um método incomum nos estudos praticados no Brasil na década de 1970 (quando esse conceito vai se consolidando na prática de análise literária de Antonio Candido a partir dos estudos sobre Memórias de um sargento de Milícias e $\mathbf{O}$ Cortiço), ${ }^{14}$ mas afinado com a acepção marxista exigente:

$\mathrm{O}$ interesse pela funcionalidade [Candido se refere à "fórmula através da qual o externo se torna interno"15]

13 Formulação apresentada no "Prefácio" de O discurso e a cidade para explicar melhor o princípio de análise empregado nos ensaios ali reunidos, dando a eles, que tratam de assuntos muito diversos, uma unidade. Ver Candido (1993, p. 9-10).

14 Referimo-nos a "Dialética da malandragem" (CANDIDO, 1993, p. 1954), estudo sobre o romance de Manuel Antônio de Almeida publicado a primeira vez em 1970, e "A passagem do dois ao três" (CANDIDO, 1974), "Literatura-sociologia" (CANDIDO, 1976) e "De Cortiço a Cortiço" (CANDIDO, 1993, p. 123-152), sobre o romance de Aluísio Azevedo, publicados em 1975, 1976 e 1991, respectivamente.

15 Viés de análise apresentado pela primeira vez no II Congresso de crítica e história literária (1961) e reformulado para publicação com o título "Crítica e sociologia (tentativa de esclarecimento)". Ver Candido (1985, p. 3-15). 
leva ao interesse pela estrutura, num sentido diferente dos estruturalistas, pois o que se indaga é como a estrutura se estrutura. Talvez tenha havido aí alguma influência do Lukács, que li em traduções italianas no começo do decênio de 1950. Mas posso dizer que não estava consciente dela quando pela primeira vez formulei aquela preocupação. (CANDIDO, 1992b, p. 233).

Trechos como esse jogam luz sobre questões difíceis de decidir, porque são de foro íntimo e raramente anunciadas em textos acadêmicos, e nos leva a intuir até que ponto afinidade de método e projeto de influência se diferenciam. Servem, ademais, para calibrar a inserção de Antonio Candido na tradição marxista: se, por um lado, ele revela leituras e acusa a inspiração, por outro, faz restrições bem pensadas. Vejamos no âmbito da crítica literária.

Como vimos, Candido possuía leitura de Lukács, com o qual expressa certa identidade - e isso, por si só, tem sua relevância, pois ele é recorrentemente citado nas entrevistas. Para situar a complexidade do caso, lembremos que durante um depoimento ele comenta a obra de Lukács a partir de perspectivas diferentes: "Nunca adotei a crítica marxista, acho, por exemplo, a crítica do Lukács, como crítica, lamentável." (CANDIDO, 1997, p. 17). Pouco adiante, refaz o juízo: "Minha ambição foi sempre fazer uma certa coisa e depois eu a vi bem formulada no Lukács." (CANDIDO, 1997, p. 21). Em jogo, uma apreciação meticulosa a respeito do encaminhamento de análise da transfiguração da realidade realizada no processo de formalização estética. Candido adere e rebate certas formulações de extração marxista, mas as pratica ele mesmo ao viabilizar os princípios mais caros àquela corrente de pensamento. A chave para essa aparente dubiedade está na diferenciação entre a concepção que 
sustenta o marxismo e a análise propriamente dita que ela põe em funcionamento. Diante disso, Candido toma partido a favor da análise de compreensão, censurando a concepção quando se mostra abrangente:

Nós [os grupos políticos a que pertencia na mocidade] nunca nos declaramos propriamente marxistas porque o marxismo é uma filosofia abrangente, muito grande, que exige quase que uma adesão para explicar todos os setores da vida. Agora, se nós concebermos o marxismo como método, ele se torna de uma flexibilidade e de uma riqueza que, ao meu ver, continua tendo muito futuro. (CANDIDO, 1997, p. 8).

A "paixão do concreto" dá forma ao materialismo inerente às reflexões e condutas de Antonio Candido - um materialismo dinâmico, autotransformador, transfigurado, e não um empirismo estático e pré-determinado.

No tocante à política, vimos que o posicionamento ideológico se deu igualmente de modo empírico, pelo exemplo de pessoas próximas a quem admirava, e de modo teórico mediante as leituras socialistas. A esses fatores podemos também acrescentar a "paixão do concreto", na medida em que a experiência com a realidade social do País forma outra dimensão de seu posicionamento de esquerda: "Fui ao nordeste [1957] e fiquei espantado de ver que aquilo que eu considerava miséria em São Paulo, era abastança no interior do Ceará. [...] Aí eu fiquei com uma visão mais materialista do Brasil.” (CANDIDO, 1997, p. 25).

A formação em sociologia decerto ofereceu a Antonio Candido instrumentos de compreensão da realidade brasileira, o que contribuiu para sua tomada de posição, mas não se pense que ela é a responsável pela acuidade dirigida às desigualdades; na 
verdade, foi o senso de desigualdade da realidade brasileira que o levou aos estudos da sociologia: "Optei pelas Ciências Sociais porque desejava entender a sociedade brasileira e porque achei que elas me punham perto do socialismo." (CANDIDO, 2006b, p. 26). Podemos fazer uma equação (em âmbito restrito) entre sociologia e ideologia: não restam dúvidas de que a primeira depurou o sentido da segunda, mas foi esta que levou àquela.

No âmbito da teoria, esse senso do concreto se desdobra em uma formulação conceitual, ou melhor, a reconstrução conceitual corresponde a uma configuração objetiva, sendo, portanto, a materialidade do fato (histórico ou literário) que determina o modo como encaminha a análise e não o contrário. Tome-se o exemplo do conceito de "estrutura" - como dissemos, de ampla circulação nas universidades brasileiras naquela época e usado livremente por historiadores, sociólogos, linguistas, críticos literários, filósofos, antropólogos, comunicólogos etc. (fato que se deve ao prestígio da escola estruturalista francesa que estava na moda). Antonio Candido travou contato com o termo "estrutura" antes, nos anos 1940, a partir dos estudos do antropólogo Radcliffe-Brown, e o usou em sua tese de sociologia. A partir do momento em que se dedica mais à crítica literária, ele conserva a funcionalidade do termo e o incorpora como o instrumento de análise: "Me apeguei ao conceito de estrutura, que depois transpus da antropologia para a crítica literária" (CANDIDO, 2001b, p. 19). Dando nome ou não de "estrutura", o certo é que a noção é usada com propósito bem definido, o que o leva ao conceito de "redução estrutural" e à estruturação de Formação da literatura brasileira, como vimos antes. Mas a peculiaridade desse conceito nesses casos se encontra menos no manuseio que Candido faz dele e mais decididamente no caráter histórico e dialético que lhe atribui: "Estrutura para mim não é a 
dos estruturalistas. É o equilíbrio dinâmico das relações internas do texto, formando o substrato da camada aparente. Vista na dimensão da história, a estrutura poderia ser concebida como sistema [...] válido para compreender a Literatura como conjunto de obras." (CANDIDO, 2006b, p. 26-27).

Notemos, primeiro, que o uso flexível do conceito garante abrangência e praticidade, fundamentando, por outro lado, o papel do conceito de "sistema", sem o qual se perde a chave de sua obra magna; segundo, que ambos adquirem valor de explicação de casos particulares, não como conceitos $a$ priori; ato contínuo, a justeza de seu uso obedece a premissas materialistas. Vale lembrar que, por mais de um motivo, sua apreensão corresponde às descobertas marxistas, especialmente em A ideologia alemã, com que lida com gosto e proveito: " $\mathrm{O}$ materialismo dialético [...] me revelou a importância das obras de juventude de Marx, como A ideologia alemã, que li mais tarde e foi o texto marxista do qual recebi maior influência". (CANDIDO, 1988b, p. 4). Apenas para situar, lembre-se de que se trata do primeiro livro propriamente marxista de Marx, no qual analisou as esferas de infraestrutura e superestrutura como categorias (da ordem do real!) antagônicas e complementares, e a partir das quais se revela a lógica dialética de uma determinada formação social.

Por outro caminho, voltamos à questão do método. O leitor que conhece os escritos de Antonio Candido, ou que acompanha suas entrevistas atesta sem dificuldade que se trata de um expositor versátil que usa disciplinas diferentes sem forçar a barra. Nos estudos literários, por exemplo, realiza incursões pelo formalismo, pelo New Criticism, pela estilística, pela sociologia etc., mas o ponto de apoio e de fuga aos impasses é um tipo específico de materialismo matizado, reflexivo e mediador, que o método dialético é capaz de explicar: 
Procuro sempre aperfeiçoar a minha relação com a empiria, quer dizer, no nosso caso é o texto, é o texto crítico, é o fato histórico na História Literária, sempre ligado ao empírico, ao concreto. E o concreto me fez sentir a sua diversidade. Repito: para poder interpretar o concreto do texto, o concreto do fato literário histórico, eu procurei sempre raciocinar como é que o oculto explica o aparente, como é que os contrários tem que ser levados em conta. Aí está uma presença constante do método dialético. (CANDIDO, 1997, p. 17).

Tudo somado, o conjunto revela o traço constitutivo da reflexão de Antonio Candido, aquilo que ele chamou de "crítica integrativa" (CANDIDO, 2006a, p. 36), baseada na variação de perspectivas para alcançar melhor a variedade dos objetos, uma atitude, por si só, materialista, pois atenta ao caráter autotransformador do concreto. ${ }^{16}$

\section{CONCLUSÃO}

Por tudo o que ficou dito, temos uma figura que se projeta devido à coerência das ideias, à postura ética, profissional e política, à contribuição intelectual de ponta, como se não bastassem os livros e artigos que vêm marcando gerações seguidas de pesquisadores e estudiosos de literatura, história, sociologia, educação etc. Contudo, como dissemos no início deste artigo, nosso interesse não é promover o culto da personalidade, como se pudéssemos esgotar em um único indivíduo um caudal intenso de tendências, encaminhamentos e respostas. Por essa escolha, sem dúvida, a contribuição de Antonio Candido estaria bem demarcada e sua pessoa reconhecida pelo trabalho e pelas conquistas; mas isso poderia incorrer em uma espécie

16 Ver a "Introdução" de Grundrisse (MARX, 2011, p. 79-64). 
de efeméride contrária à índole discreta do personagem, além de desdizer o método de análise que ele conseguiu depurar, baseado na inserção do objeto em seu contexto correspondente e significativo, pois tão importante quanto o tema de reflexão é o processo no qual ele se insere.

Analisando-se as entrevistas de Antonio Candido, percebese que ele próprio toma recuo de sua pessoa e a situa no jogo de forças (pessoais, históricas, políticas etc.) da época vivida, pontuando a dialética entre obra, vida e mundo de maneira despretensiosa, fazendo parecer natural o que na verdade é um resultado de forças dirigidas: "Sou um homem dependente do decênio de 1930" (CANDIDO, 1997, p. 14). ${ }^{17}$ Ora, como se sabe, a década de 1930 foi palco de mudanças tremendas, que levavam a uma superação mais seletiva e definitiva dos resíduos oitocentistas que sobreviveram à passagem do século, resquícios que souberam, no entanto, contornar as consequências de grandes eventos, como a abolição da escravidão e a proclamação da República, que, afinal, não se confirmaram como tão grandes assim. ${ }^{18}$ Também no âmbito da cultura, o verniz da Belle Époque e a eclosão do modernismo não foram suficientes para superar as iniquidades políticas e econômicas da modernização de molde burguês-capitalista que representavam. ${ }^{19}$

${ }^{17}$ É comum encontrar, nas entrevistas, referências à década de 1930 e sua influência sobre Antonio Candido e sua geração. Em uma dessas passagens, lemos: "O decênio de 1930 foi de fermentação e de opções drásticas para a mocidade, levando-nos a nos politizarmos, não apenas em função do Brasil, mas dos acontecimentos internacionais. [...] Havia uma onda de radicalização que percorreu todo o decênio de 1930 e da qual tenho saudade. Muita saudade, mesmo, porque parecia que as coisas iam dar certo. Que íamos lutar contra o fascismo, íamos derrubá-lo e abrir caminho para o socialismo." (CANDIDO, 2001b, p. 7). Ver também, "Literatura e cultura de 1900 a 1945" (CANDIDO, 1985, p. 109-138).

18 Ver Oliveira (2018).

19 Ver Prado (2010). 
A década de 1930 trouxe uma série de condicionantes que um indivíduo sensível às demandas de uma sociedade desalinhada saberia aproveitar. Mais do que isso, as ocorrências do período se sedimentaram nas múltiplas dimensões da vida, fazendo confluir o interesse intelectual (sem ser necessariamente acadêmico) e a atividade política (sem ser necessariamente partidária) no fluxo das transformações do País e do mundo; além disso, atravessam e dão lastro às linhas de força que delimitam um raio de ação e que foram nosso objeto de análise: a opção pela clareza (na medida em que sacudia fora o ranço bolorento da linguagem "especializada"), ${ }^{20} \mathrm{o}$ viés de esquerda (premido pela disputa ideológica entre fascismo, socialismo e liberalismo, que se formalizou no período entreguerras) e o pendor materialista (atitude realimentada pela urgência de pensar os impasses do desenvolvimento social brasileiro).

Estamos diante da reprodução peculiar (porque o contexto e a personalidade são outros) daquele "sentimento íntimo" de que falava Machado de Assis: ${ }^{21}$ cabe ao intelectual interessado na realidade apresentada por seu tempo e País tomar providências, mesmo quando a sociedade como um todo não dá por elas.

\section{Referências}

ABRAMOVICH, Fanny. O mestre dos grandes mestres. In: ABRAMOVICH, Fanny. Quem educa quem? São Paulo: Círculo do livro, 1990. p. 105-136.

${ }^{20} \mathrm{O}$ que se deve em grande parte a publicações que impressionaram aquela geração, como Casa grande \& senzala e Raízes do Brasil. Ver Candido (2006e).

${ }^{21}$ Assis (2008). 
ARANTES, Paulo Eduardo. Sentimento da dialética na experiência intelectual brasileira: dialética e dualidade segundo Antonio Candido e Roberto Schwarz. São Paulo: Paz e Terra, 1992.

ARRIGUCCI JR., Davi. Movimentos de um leitor. In: D'INCAO, Maria Angela; SCARABÔTOLO, Eloísa Faria (org.). Dentro do texto, dentro da vida: ensaios sobre Antonio Candido. São Paulo: Companhia das Letras: Instituto Moreira Sales, 1992. p. 181-204.

ASSIS, Machado de. Notícia da atual literatura brasileira: instinto de nacionalidade. In: ASSIS, Machado de. Obras completas em quatro volumes. Rio de Janeiro: Nova Aguilar, 2008. v. 3, p. 1203-1211.

CANDIDO, Antonio. A passagem do dois ao três (contribuição para o estudo das mediações na análise literária). Revista de história, São Paulo, v. L, n. 100, p. 787-799, out./nov., 1974.

CANDIDO, Antonio. Literatura-Sociologia: análise de "O cortiço" de Aluísio Azevedo. Cadernos da PUC, Rio de Janeiro, n. 28, p. 121-134, 1976.

CANDIDO, Antonio. La literatura de América Latina: unidad y conflicto. [Entrevista cedida a] Beatriz Sarlo. Punto de Vista. Buenos Aires, n. 8, mar./jun. 1980, p. 3-9.

CANDIDO, Antonio. Crítica e sociologia (tentativa de esclarecimento). In: CANDIDO, Antonio. Literatura e sociedade: estudos de teoria e história literária. 7 ed. São Paulo: Ed. Nacional, 1985. p. 3-15.

CANDIDO, Antonio. O método crítico de Sílvio Romero. São Paulo: Edusp, 1988a.

CANDIDO, Antonio. Antonio Candido: a militância por dever de consciência. [Entrevista cedida a] Eder Sader e Eugênio Bucci. Teoria \& Debate. São Paulo, n. 2, mar., 1988b, p. 1-11. Disponível em: <https://teoriaedebate.org.br/1988/03/01/amilitancia-por-dever-de-consciencia/>. Acesso em: 6 fev. 2019. 
CANDIDO, Antonio. Teresina e seus amigos. In: CANDIDO, Antonio. Teresina etc. 2 ed. São Paulo: Paz e Terra, 1992a. p. 13-73.

CANDIDO, Antonio. Entrevista. CANDIDO, Antonio. Brigada ligeira e outros escritos. São Paulo: Ed. Unesp, 1992b. p. 229246.

CANDIDO, Antonio. O discurso e a cidade. São Paulo: Duas Cidades, 1993.

CANDIDO, Antonio. Marxismo e militância. [Entrevista cedida a] José Pedro Renzi. Praga: revista de estudos marxistas, São Paulo, n.1, set./dez. 1996, p. 5-26.

CANDIDO, Antonio. Entrevista com Antonio Candido. [Entrevista cedida a] Aldo Lima et al. Investigações: linguística e teoria literária, Recife, v. 7, set., 1997, p. 7- 39. Disponível em: $<$ https://periodicos.ufpe.br/revistas/INV/issue/view/92>. Acesso em: 8 fev. 2019.

CANDIDO, Antonio. Na sala de aula: caderno de análises literárias. 7 ed. São Paulo: Editora Ática, 1999.

CANDIDO, Antonio. Os parceiros do Rio Bonito: estudos sobre o caipira paulista e a transformação de seus meios de vida. 9 ed. São Paulo: Duas Cidades; Ed. 34, 2001a.

CANDIDO, Antonio. Entrevista com Antonio Candido. [Entrevista cedida a] Heloísa Pontes. Revista Brasileira de Ciências Sociais, São Paulo, v. 16, n. 47, out. 2001b, p. 1-31. Disponível em: <http://www.scielo.br/scielo.php?pid=S0102$69092001000300001 \&$ script $=$ sci_abstract\&tlng $=p t>$. Acesso em: 10 fev. 2019.

CANDIDO, Antonio. Entrevista. In: JACKSON, Luiz Carlos. A tradição esquecida: Os parceiros do rio Bonito e a sociologia de Antonio Candido. Belo Horizonte: UFMG. São Paulo: Fapesp, 2002. p. 125-176. 
CANDIDO, Antonio. Antonio Candido. [Entrevista cedida a] Luís Augusto Fischer. Literatura e sociedade, São Paulo, v. 14, n. 12, dez., 2006a, p. 28-37. Disponível em: $<$ http://www.revistas. usp.br/ls/article/view/25198/26984>. Acesso em: 6 fev. 2019.

CANDIDO, Antonio. A experiência hispano-americana de Antonio Candido. [Entrevista cedida a] Pablo Rocca. Literatura e sociedade. São Paulo, v. 14, n. 12, dez., 2006b, p. 18-27. Disponível em: <www.revistas.usp.br/ls/article/view/25197/26983>. Acesso em: 6 fev. 2019.

CANDIDO, Antonio. Formação da literatura brasileira: momentos decisivos, 1750-1880. 10. ed. Rio de Janeiro: Ouro sobre Azul, 2006c.

CANDIDO, Antonio. O estudo analítico do poema. 5 ed. São Paulo: Associação Editorial Humanitas, 2006d.

CANDIDO, Antonio. O significado de Raízes do Brasil. In: HOLANDA, Sérgio Buarque de. Raízes do Brasil. São Paulo: Companhia das Letras, 2006e. p. 235-250.

CANDIDO, Antonio. A literatura é uma transfiguração da realidade. [Entrevista cedida a] Luís Augusto Fischer et al. O eixo e a roda: Revista de literatura brasileira, Belo Horizonte, v. 20, n. 1, jan./jun., 2011a, p. 157-162.

CANDIDO, Antonio. O socialismo é uma doutrina triunfante. [Entrevista concedida a] Joana Tavares. Brasil de fato, Rio de Janeiro, ago., 2011b, p. 1-7.

CANDIDO,Antonio. Entrevista com Antonio Candido. [Entrevista cedida a] Jorge Coli. Aurora: revista de arte, mídia e política. São Paulo, v. 10, n. 32, jun./set., 2018, p. 172-183. Disponível em: $<$ http://ken.pucsp.br/aurora/article/view/39695/27033>. Acesso em: 10 fev. 2019.

CARDOSO, Fernando Henrique. Um ex-aluno. In: D'INCAO, Maria Angela; SCARABÔTOLO, Eloísa Faria (org.). Dentro do texto, dentro da vida: ensaios sobre Antonio Candido. São Paulo: Companhia das Letras: Instituto Moreira Sales, 1992. p. 37-40. 
Antonio Candido por ele mesmo: a entrevista como momento de mediação

CARVALHOSA, Modesto. Educação, universidade e movimento docente. In: AGUIAR, Flávio (org.). Antonio Candido: pensamento e militância. São Paulo: Fundação Perseu Abramo: Humanitas/FFLCH/USP, 1999. p. 219-236.

CHIAPPINI, Ligia. Um mestre no ensino e no ensaio. In:AGUIAR, Flávio (org.). Antonio Candido: pensamento e militância. São Paulo: Fundação Perseu Abramo: Humanitas/FFLCH/USP, 1999. p. 52-60.

CLARO, Sílvia Mussi da Silva. O ensaio e aula. In: D’INCAO, Maria Angela; SCARABÔTOLO, Eloísa Faria (org.). Dentro do texto, dentro da vida: ensaios sobre Antonio Candido. São Paulo: Companhia das Letras: Instituto Moreira Sales, 1992. p. 213-217.

DANTAS, Vinícius (org.). Bibliografia de Antonio Candido. São Paulo: Duas Cidades; Ed. 34, 2002. 2 v.

FERNANDES, Florestan. O mestre exemplar. In: D'INCAO, Maria Angela; SCARABÔTOLO, Eloísa Faria (org.). Dentro do texto, dentro da vida: ensaios sobre Antonio Candido. São Paulo: Companhia das Letras: Instituto Moreira Sales, 1992. p. 33-36.

KONDER, Leandro. A derrota da dialética. Rio de Janeiro: Campus, 1988.

MARX, Karl. Grundrisse: manuscritos econômicos de 18571858; esboços da crítica da economia política. São Paulo: Boitempo; Rio de Janeiro: Ed. UFRJ, 2011.

MORAES, João Quartim de. A evolução da consciência política dos marxistas brasileiros. In: MORAES, João Quartim de (org.). História do marxismo no Brasil: os influxos teóricos. Campinas: Unicamp, 1995. v. 2, p. 45-100.

MOURA, Flávio; MONTERO, Paula (org.). Retrato de grupo: 40 anos do Cebrap. São Paulo: Cosac Naify, 2009. 
OLIVEIRA, Francisco de. O adeus do futuro ao país do futuro: uma biografia breve do Brasil. In: OLIVEIRA, Francisco de. Brasil: uma biografia não autorizada. São Paulo: Boitempo, 2018.

PRADO, Antonio Arnoni. Itinerário de uma falsa vanguarda: os dissidentes, a Semana de 22 e o Integralismo. São Paulo: Ed. 34, 2010.

SCHWARZ, Roberto et al. Nós que amávamos tanto "O capital": leituras de Marx no Brasil. São Paulo: Boitempo, 2017. SCHWARZ, Roberto. Pressupostos, salvo engano, de "Dialética da malandragem". In: SCHWARZ, Roberto. Que horas são? São Paulo: Companhia das Letras, 1989. p. 129-155.

TRÊS ANTÔNIOS e um Jobim (1993). Direção: Rodolfo Brandão. Produção: Augusto Casé. Entrevista: Zuenir Ventura. Rio de Janeiro: Elipse Televisão \& Cinema, 2017. (MédiaMetragem).

WAIZBORT, Leopoldo. A passagem do três ao um: crítica literária, sociologia, filologia. São Paulo: Cosac Naify, 2007. 